\title{
Scientific rationality, uncertainty and the governance of human genetics: an interview study with researchers at deCODE genetics
}

\author{
Stefán Hjörleifsson*,1 and Edvin Schei ${ }^{1}$ \\ ${ }^{1}$ Section for general practice, Department of Public Health and Primary Health Care, University of Bergen, Norway
}

Technology development in human genetics is fraught with uncertainty, controversy and unresolved moral issues, and industry scientists are sometimes accused of neglecting the implications of their work. The present study was carried out to elicit industry scientists' reflections on the relationship between commercial, scientific and ethical dimensions of present day genetics and the resources needed for robust governance of new technologies. Interviewing scientists of the company deCODE genetics in Iceland, we found that in spite of optimism, the informants revealed ambiguity and uncertainty concerning the use of human genetic technologies for the prevention of common diseases. They concurred that uncritical marketing of scientific success might cause exaggerated public expectations of health benefits from genetics, with the risk of backfiring and causing resistance to genetics in the population. On the other hand, the scientists did not address dilemmas arising from the commercial nature of their own employer. Although the scientists tended to describe public fear as irrational, they identified issues where scepticism might be well founded and explored examples where they, despite expert knowledge, held ambiguous or tentative personal views on the use of predictive genetic technologies. The rationality of science was not seen as sufficient to ensure beneficial governance of new technologies. The reflexivity and suspension of judgement demonstrated in the interviews exemplify productive features of moral deliberation in complex situations. Scientists should take part in dialogues concerning the governance of genetic technologies, acknowledge any vested interests, and use their expertise to highlight, not conceal the technical and moral complexity involved.

European Journal of Human Genetics (2006) 14, 802-808. doi:10.1038/sj.ejhg.5201626; published online 19 April 2006

Keywords: governance; ethics; genetic testing; qualitative research; industry research

Introduction

This paper presents an interview study of industryemployed scientists' reflections on the consequences of human genetic technologies on the lives of 'ordinary' people, focusing on scientific, commercial and regulatory

*Correspondence: Dr S Hjörleifsson, Section for General Practice, Department of Public Health and Primary Health Care, University of Bergen, Kalfarveien 31, Bergen 5018, Norway. Tel: + 47555 86137; Fax: + 475558 6130; E-mail: stefan.hjorleifsson@isf.uib.no

Received 4 October 2005; revised 2 March 2006; accepted 7 March 2006; published online 19 April 2006 aspects and the perceived rationality of public reactions to new technologies.

Human genetics poses a challenge to society's mechanisms for regulating science and technology. Academia and industry are increasingly intertwined; ${ }^{1}$ the private sector plays a crucial part in genetic research and technology development. ${ }^{2}$ The sentiments of the public regarding the new genetics are diverse, ${ }^{3,4}$ ranging from fear that not enough precaution is being taken with regard to adverse effects, or that the sacredness of human life is being insulted, to the opposite worries, that undue restrictions deprive suffering individuals of crucial health benefits. 
Some are less than confident that the authorities are sufficiently protecting the interests of patients or others from the financial motives of biotechnology companies or from 'runaway' science. In many countries, the political regulation of related issues such as genetic modification of organisms, reproductive technologies and stem cell research, has been subject to widespread controversy, public reactions are at times acrimonious, and regulations imposed by governments have put considerable restraints on research.

Several European countries as well as the United States and Canada have taken steps towards participatory governance of human genetics, that is the public is invited to consultations, lay participation is increased in advisory boards, and transparency and accountability are promoted by different measures. ${ }^{5,6}$ The founders of the UK Biobank, which is to be the world's largest resource for population genetic research, have committed themselves to a public governance and consultation policy. ${ }^{7}$ The goals of public engagement are a subject of controversy, however. ${ }^{8}$ Public consultation and apparent transparency may be designed to promote genetic literacy and secure compliance with established policy, as when scientific advice is seen as sufficient to guide policy. ${ }^{9}$ Otherwise, such processes may shift power towards the public, to the point of overruling expert opinions on science and technology policy. ${ }^{10}$ Tensions between different perspectives on public involvement have gained importance in light of recent evidence that the relationship between scientific authority, public interests and governance is unstable in several arenas involving biotechnology and medicine. ${ }^{5,11}$

There is anecdotal ${ }^{12}$ and broader ${ }^{13}$ evidence that commercial interests in the biotechnology sector sometimes run counter to the interests of the general public. Some critics argue that researchers tend to bother less about the social impact of their work as they become involved with industry. ${ }^{14,15}$ Such claims are not easy to substantiate, but the meltdown of traditional distinctions between academia and industry, and between basic and clinical research, suggests a cautious attitude towards the underlying motives and self-proclaimed moral values involved in the search for knowledge. ${ }^{1,16,17}$

The perceptions of scientists who engage in human genetics about moral issues have not been widely investigated. In 2003, however, a survey of more than 1200 geneticists in the United States demonstrated a tension between the highly valued rights of nonexpert individuals to decide how to avail themselves of genetic technologies and the equally clear opinion that expert knowledge provides a privileged position when it comes to making decisions about the use of those technologies. ${ }^{18}$ And in an interview study from 1997 senior scientists and clinicians in human genetics in the United Kingdom were found to be eager to maintain the distinction between 'objective science' and 'the public sphere', preserving their profes- sional power as counsellors to policy-makers and educators of the public. ${ }^{19}$ The influence of commercial attachments on expert deliberation was not addressed in the above studies. And though ethical challenges involved in commercialization have been discussed in recent literature, ${ }^{16,17}$ the only study of which we are aware that addresses how scientists engaged in human genetics view such challenges is a survey demonstrating in broad terms that commercialization is a cause of concern within the human genetics community in the United States. ${ }^{20}$

In order to elicit in-depth reflections and deliberations among our informants, we chose a qualitative design, and conducted focus group interviews with scientists working for deCODE genetics in Iceland. deCODE is a controversial research enterprise conspicuous to Icelandic society, and has attracted international interest. The company's recent history exemplifies many aspects of the dynamics between expert knowledge, commercial interests and public expectations in the field of emerging genetic technologies. ${ }^{21,22}$ The company announces that it is 'delivering on the promise of the new genetics,' and boasts success in identifying and exploring targets for pharmaceutical interventions and genetic tests for a range of diseases, including myocardial infarction ${ }^{23}$ stroke, asthma, osteoporosis and schizophrenia. More than 100000 Icelanders - approximately $50 \%$ of the country's adult population - have volunteered blood samples to deCODE (www.decode.com).

\section{Materials and methods}

Qualitative methods, while not providing material for statistical generalizations, are appropriate for in-depth exploration of complex opinions, values and reasoning. ${ }^{24}$ Our informants comprised 13 individuals of both sexes, Icelanders and non-Icelanders, physicians and biologists, and were recruited among scientists at deCODE on the basis of their interest in participating in interviews on the topic of genetics and society which had been announced through individual discussions and a plenary presentation within the company. No differences between the sample of informants and the scientific staff at deCODE in general were observed. The informants were interviewed by SH in English (the main working language of the company) in three focus group lasting $2 \mathrm{~h}$; two groups of four and one consisting of five scientists. All interviews were conducted within 1 week in October 2003, and a partial first coding and analysis was performed between the interviews. A semistructured approach was used: The scientists were asked to identify and pursue any likely consequences that human genetic research may have in the lives of 'ordinary people'. They were encouraged to draw upon examples from their own professional and private experience in the discussion, and it was explained that the aim of the discussion was to explore rather than necessarily to agree 
on any definite views on the topics given. In accordance with principles for focus group interviews ${ }^{25-27}$ the investigator encouraged exploration of key topics introduced by the informants themselves, such as the complexity of genetic prediction and the potentially vested interests of research companies. Full audiotape recordings were transcribed verbatim and supplemented with written notes by $\mathrm{SH}$. All transcripts were coded for emerging themes and analysed through a reflective process. ${ }^{28,29} \mathrm{SH}$ provided the initial coding and both authors then challenged the suggested classification iteratively until a final coding was achieved. In this process, the authors sought, through use of conflicting hypotheses, to take account of how their own preconceptions, including the view that the dialogue between science and society ought to be strengthened, might influence the analysis.

\section{Results \\ Confusing genetic information, overzealous marketing of scientific products and escalating inequality}

How are we going to approach this? I mean, you get a haplotype for a certain disease, and it increases your risk maybe two-fold. But even if you have the particular haplotype, you may not necessarily get the disease. ... People may just think 'God, I have the haplotype so I am going to get stroke or whatever.' If diagnostics appear on the market before the therapies ... anxiety may get higher before it gets less.

Although strongly enthusiastic about their own work, the scientists identified and discussed a range of concerns having to do with the impact of human genetics on society in general and prevention of common diseases by means of genetic technologies in particular, expressing their satisfaction with this opportunity to 'discuss how what you're doing is going to influence others.' The majority of these concerns were connected by a common thread: the implications of genetic information are often hard to establish, as in the case of predictive testing which is of a probabilistic nature and will in many instances be introduced in advance of effective treatment. There is a danger that oversimplification may entail overselling of new technologies by commercial stake holders, researchers and the media. All this can result in confusion and disappointment about genetic technologies, as well as increasing the cost of healthcare with little or no benefit. Frustration may add to current scepticism towards genetics among the public. In addition, the scientists recognised that there is the danger that social injustice and disparities in health will be propagated on a global or a local scale through the introduction of technologies affordable to the well off only.

\section{Dilemmas resulting from the commercialization of research}

On several occasions, the scientists remarked that the field of healthcare and medical research is loaded with vested interests. Many players have a strong motivation to make profit from research, pharmaceutical products or other technologies:

It's 'follow the buck'. The pharmaceutical industry driving a lot of the research and funding ... if half the population were taking this drug or that pill from 20 to 80 every day, of course it is vast amounts of money.

There is a danger that consumers and healthcare providers will be hoaxed into using genetic technologies on weak indications. Along similar lines, the scientists mentioned that many people have found it alarming that deCODE, as a commercial enterprise, was given monopoly license to operate the Icelandic Health Sector Database which was meant to contain medical information about the entire nation.

At no time, however, did our informants venture doubts or reflections about potential conflicts between the commercial goals of their own employer and the intellectual and ethical purposes advanced in public debate. Neither did they express concern that their own employment status might sway their own reasoning. When vested interests, social injustice or related issues were discussed by the scientists themselves, the investigator invited further comments and reflections, but on no occasion did the scientists take the opportunity to ponder in what way deCODE's research and public strategies might be influenced by financial considerations, nor did they bring the discussion to bear on how their own intellectual or moral positions might be influenced by commercial motives on behalf of their employer.

Rather, by omission, any mentioning of financial considerations among biotechnology companies or overzealous marketing of human genetics was made as if such motives and fallacies could impact other players in the field, but not deCODE. Similarly, when it came to their individual positions, the scientists simply described themselves as committed to the welfare of the public, sharing 'a naive wish to be able to contribute to a cure', and seemed unaware that other aspirations and incentives, such as scientific success, financial gain or public acknowledgement, might influence their worldview and judgement.

\section{Rational and irrational fear of genetics}

A certain ambiguity could be detected in the scientists' discussion of moral issues and public perceptions of genetics:

Most technologies can either be used effectively and safely, but they can also be abused. And I think it is 
the fear of abuse that drives the negative response to genetics in society ... have to find ways to overcome that fear.

This informant starts by highlighting that technology actually can be abused, and seems to argue that the way of overcoming public fear is to prevent abuse of technologies. On other occasions however, this informant as well as others speak about an 'irrational' fear of genetics among the public, 'a lot of heresy and misconceptions' and 'basic mistrust of scientists' which must be eliminated for the sake of efficient introduction of technology. The public was described as fearful and fascinated, rational and irrational. The interviews thus reveal a tension between a critical stance towards an alleged fear of genetics in a stereotyped 'public', and the view that genetics really has the potential to be used inappropriately, in which case public anxiety is in fact rational.

\section{Science and the governance of genetics}

The scientists stated that society must develop the means to ensure that genetic technologies are used in ways that are beneficial to all, that is, to avoid useless testing, to avoid misunderstanding of results, and to avoid that barriers to access prevent the poor from benefiting from genetic technologies:

Technology needs to advance hand in hand with the maturity to use it ... the moral and spiritual advances in the society.

One group raised the point that Icelandic society is not conducting the debate necessary to prepare for the use of genetic technologies. When prompted, the scientists in this group suggested that the responsibility for engaging the public in debate about new technologies should rest on universities, health authorities, the medical profession and the church. One scientist also suggested that companies developing genetic technologies should fund initiatives to raise public debate. This was met by approval by the group.

In addition to 'maturity to use technology' and 'moral and spiritual advances', the informants saw 'political will' and 'ethical thinking' as prerequisites for the governance of human genetics. They saw such processes and abilities as qualitatively different from the mental processes involved in the development of technology itself. An example of this is seen in a discussion about the role of the health authorities, universities and the church:

Even if we as scientists do not necessarily take them very seriously when they start talking, the majority of the people would. I think it is very important for them to enter this debate.

\section{Contradictions, tentative positions and suspension of judgement}

Issues of complexity and uncertainty were explored by our informants through discussions of hypothetical genetic tests and the clinical epidemiology of established risk factors, including serum-cholesterol levels estimating cardiovascular risk and bone mineral density measurement to estimate risk of osteoporosis. Several informants stated personal opinions or preferences in apparent opposition to their general lines of argument. The following quotation is from a scientist who earlier in the same interview argued without reservation that the value of predictive testing lies in the opportunity to change one's lifestyle and to benefit from preventive medications:

...the stroke haplotype. There is a lot of stroke in my family, and I'm dying to know if I have that haplotype or not, but what I would do with it? I would not really change my life or anything. But would I take a [hypothetical] pill to prevent. Based on that haplotype? No.

Even when prompted directly, individual scientists could not always state the exact reasons for personal inclinations to take a predictive test or not, or the meaning such tests would hold to them. Personal opinions were frequently debated, exploring arguments for and against, without the scientists' clearly or finally committing themselves to the different positions submitted, as in the following discussion about the value of a hypothetical predictive genetic test for osteoporosis:

A: You might check your bone density more often, you would take hormones when you reach menopause and do things that help.

B: Well, you can scan your bones every other year, but does it matter?

B: ... then you have the increased risk of breast cancer ... [or other side effects]

Though the discussion on this issue was rather long, no final verdict on the test in question or the preventive measures available was passed, and scientist $C$, who stated that she was interested in knowing her personal results of such a test for 'security' reasons, was in doubt as to whether the results would lead to lifestyle changes or not.

\section{Discussion}

Our informants identified important challenges and problems concerning the use of human genetic technologies for health purposes, but did not express second thoughts about policy decisions involved in their own research. They concurred that overzealous marketing may backfire and cause the public to become more sceptical of 
genetics, but seemed unaware that commercial interests might influence deCODE's policy or the viewpoints of the informants themselves. They stated that the governance of human genetics relies on moral principles external to scientific rationality itself, and when engaging with questions of how they themselves would make use of genetic technologies they demonstrated ambivalence and suspension of judgement rather than clear-cut answers and opinions.

Following some methodological comments, we will discuss possible interpretations and implications of our findings, in particular the relationship between the rationality of science and the theoretical and practical demands of governance.

Owing to practical constraints, the interviews were conducted within a short interval, providing little time for the preliminary analysis of the data that might have revealed the need to revise the interview strategy in order to supplement or challenge the initial findings. In our analysis, however, we have not been found indications that a revision of the interview strategy along the way would have added decisively to the validity of our results.

We faced the question of whether to confront our informants with explicit questions about the potential interference between their own employment positions and subjective perceptions, interpretations and moral judgement concerning the use of human genetics. This would undoubtedly have unleashed interesting reflections in the groups. The multilayered interpretation of such reflections would remain; however, strategic motives for expressing or concealing opinions could not be eliminated. We therefore chose to let the interviews develop by simply encouraging our informants to pursue their own reflections on how genetics might impact on the lives of ordinary people. Interestingly, critical self-reflection did not arise in any of the groups. How should this be interpreted?

Our informants may have been motivated by strategic reasons to picture themselves, and by implication deCODE, as socially responsible, by paying lip service to worries and ethical concerns about genetic technologies, while intentionally avoiding potentially discomforting reflections on their own positions. Strategic self-portrayal is not unknown in the biotechnology world. A recent study among biotechnology entrepreneurs on the capital markets in New York city has shown that the self-portrayal of this industry is pervasively influenced by the requirement for cash. ${ }^{30}$ Previous studies have demonstrated how deCODE promotes a favourable image of the company and its research, ${ }^{31,32}$ a requirement for funding as well as public and healthcare cooperation in research projects. Although public anxiety about genetics can obviously constitute an impediment to deCODE's interests, openly criticising the public for irrational attitudes towards genetics could do more harm than good. The ambiguity encountered among our informants regarding public suspicion of genetics might therefore reflect a tension between the opinion that public anxiety is an irrational impediment to business, and the strategic insight that this anxiety must somehow be respected even if irrational.

The eagerness demonstrated by our informants to engage in the interviews, however, as well as other behavioural aspects, including the tentativeness and uncertainty revealed in their dialogues, indicate that the lack of critical reflection regarding their own and deCODE's positions was a genuine expression of these scientists' moral self understanding, and not a strategic stance to protect themselves or their employer. This finding is consistent with the social psychological theory of cognitive dissonance, which describes how people suppress from consciousness certain attributes of their acts and motives in order to maintain a consistent and positive self understanding. ${ }^{33}$ It is our impression that the informants share a genuine moral sensitivity to challenges raised by the genetic technologies they are contributing to. This perspective may, however, also coexist with strategic motives such as the one noted above; namely that public anxiety is an impediment to business and has to be taken seriously in order to 'neutralize' it.

The scientists' call for societal regulation of genetic technologies resonates with the philosophical tradition claiming that the regulation and use of science cannot be guided successfully by the principles of science itself. Already Aristotle held that theoretical reasoning and technical knowledge involved in human well-fare should be guided by a moral-practical rationality, a faculty of judgement concerned not only with the right actions to achieve a given end, but also the identification of valuable ends, as well as the positive and negative contribution of a given means to different ends. On the view of social philosopher Jürgen Habermas, the rationality of an engineering science does not automatically bring benefits to mankind. For this to happen, the engineering disciplines must be managed by institutions embodying sound moral principles and appropriate procedures for judging the pros and cons of new developments. The successful regulation of novel technologies does not follow the same rules as does science itself, and should be judged by other standards. ${ }^{34,35}$ Our informants identified complex and intriguing questions regarding how the means provided by human genetic technologies can contribute to the end of improving health without causing anxiety and injustice or inappropriately increasing expenses, and their arguments further imply that these questions are in the domain of a moral-practical rationality qualitatively different from that of scientific knowledge and technology itself.

Some of the challenges of predictive testing are easily illustrated by the case of osteoporosis, a clinical entity researched by deCODE and discussed by our informants. Despite the increased risk of fractures in osteoporotic women, most women with low bone mineral density will 
not suffer fractures, and most fractures among older women do in fact occur in individuals with normal bone mineral density. ${ }^{36}$ Also, the preventive measures available to women 'at risk' do not eliminate the risk of adverse outcome. ${ }^{37}$ Because of the probabilistic nature of predictive testing, the incomplete effect of prevention, side effects and economic costs, as well as contending social and individual values, the use of bone mineral density measurement and preventive measures against osteoporosis-related fractures is not necessarily of universal benefit for women and society. In keeping with conclusions drawn in recent litterature, ${ }^{6,38-40}$ our informants seem to acknowledge that predictive testing and preventive measures against osteoporosis and other common diseases based on genetic technologies will be compounded by similar complexity.

Our informants conceded that genetics professionals do not hold privileged perspectives on the value-laden questions of how genetic technologies should be used. However, as stated above we also found some evidence of the view that public opinions may be frankly irrational, science itself providing sufficient guidance for the implementation of genetic technologies. The latter view corresponds to the results from an interview study by Kerr, Cunningham-Burley and Amos, according to which genetics professionals in the United Kingdom tended to define their professional knowledge as exempt from social and commercial influence. ${ }^{19}$ If this stance was less prominent in our study, this may be a consequence of the uncompromising debate conducted between 1997 and 2000 in Iceland and internationally about deCODE's plans for the Icelandic Health Sector Database. ${ }^{21,22,41}$ For deCODE, the opposition and the subsequent regulation imposed by Icelandic authorities must have been an uncomfortable reminder of how easily plans, which from the researchers' point of view may be motivated by nothing but a visionary blend of scientific logic, bravery and industriousness, can be disrupted by unanticipated societal forces.

The personal uncertainty among our informants regarding how to make use of genetic technologies illustrates that in the face of scientific, moral and health-related uncertainty, deliberation involves exploring different perspectives and value-claims, and their conflicting relationships. In discussions of what is morally right and appropriate, temporary suspension of judgement and investigation of complexity and ambiguity is required. ${ }^{42}$

Further, the points of view offered by our informants do not necessarily express opinions and attitudes of which they were cognisant before the interviews. They are the products of a dialogue, where the dynamics of the interviews influence the scientists' negotiation of meanings and stances. ${ }^{43}$ We believe that we were able to avoid fruitless 'demonising' of industry and take seriously the ability and willingness of our informants to critically reflect upon their own activities, ${ }^{44}$ thereby producing new insight among themselves, which hopefully will serve as input into the broader debate about genetics, commercialization and governance.

Certain clues about rational governance of challenging technology development in genetics may be inferred from the results of the present study. What we have demonstrated on a microscopic level - acknowledgement of complexity, tentative suspension of judgement and collective exploration of arguments and opinions - are likely to be crucial features of any deliberative rationality able to manage the products of human genetic research. In our opinion, scientists share the responsibility for highlighting uncertainty and dilemmas, thereby stimulating public deliberation. They also need to acknowledge that vested interests of a commercial nature may interfere with scientific and moral judgments in the pursuit and governance of genetics. Public deliberation on the use of genetic technologies is valueless without scientific insight, but the expertise should be used to explore and explain, not conceal or trivialise, the technical and moral complexity of the issues.

\section{Acknowledgements}

The study was supported by a grant from the Norwegian Research Council, Grant no. 147640/330, and by a mobility scholarship from the Nordic Research Board, Grant no. 030444. We thank the scientists from deCODE genetics for their generous assistance and Kristin $E$ Harðardóttir, and the anonymous reviewers for their valuable comments.

\section{References}

1 Gibbons M: Science's new social contract with society. Nature 1999; 402: C81-C84

2 Caulfield T: The commercialization of human genetics: profits and problems. Mol Med Today 1998; 4: 148-150.

3 Hargreaves I, Lewis J, Speers T: Towards a Better Map: Science, The Public and The Media. UK: Economic and Social Research Council, 2003.

4 European Commission. Europeans and Biotechnology in 2002, European Comisson, 2003.

5 Jones M, Salter B: The governance of human genetics: policy discourse and constructions of public trust. New Genet Soc 2003; 22: $21-41$.

6 Expert group on genetic testing: Ethical, Legal and Social Aspects of Genetic Testing: Research, Development and Clinical Applications. Brussels: European Commission, 2004.

7 Setting standards: The UK Biobank ethics and governance framework http://www.ukbiobank.ac.uk/ethics/efg.php accessed on November 30th 2005.

8 Rowe G, Frewer LJ: A typology of public engagement mechanisms. Sci, Technol Hum Values 2005; 30: 251.

9 Petersen A: Securing our genetic health: engendering trust in UK Biobank. Sociol Health Illness 2005; 27: 271-292.

10 Levitt M: Public consultation in bioethics. What's the point of asking the public when they have neither scientific nor ethical expertise? Health Care Anal 2003; 11: 15-25.

11 Frewer L: Risk perception, social trust, and public participation in strategic decision making: implications for emerging technologies. Ambio 1999; 28: 569-574. 
12 Horton R: Vioxx, the implosion of Merck, and aftershocks at the FDA. Lancet 2004; 364: 1995-1996.

13 Cho MK, Illangasekare S, Weaver MA, Leonard DGB, Merz JF: Effects of patents and licenses on the provision of clinical genetic testing services. J Mol Diagn 2003; 5: 3-8.

14 Krimsky S: Science in the Private Interest: Has the Lure of Profits Corrupted Biomedical Research? Rowman and Littlefield: Lanham, 2003.

15 Rowland R: Living laboratories: Women and Reproductive Technologies. Bloomington: Indiana University Press, 1992.

16 Ziman J: Why must scientists become more ethically sensitive than they used to be? Science 1998; 282: 1813-1814.

17 Andrews L, Nelkin D: Body Bazaar: The Market for Human Tissue in the Biotechnology Age. Crown Publishers: New York, 2001.

18 Rabino I: Genetic testing and its implications: Human genetics researchers grapple with ethical issues. Sci Technol Hum Values 2003; 28: 365-402.

19 Kerr A, Cunningham-Burley S, Amos A: The new genetics: professionals' discursive boundaries. Sociol Rev 1997; 45: 279303

20 Rabino I: How human geneticists in US view commercialization of the Human Genome Project. Nat Genet 2001; 29: 15-16.

21 Merz JF, McGee GE, Sankar P: 'Iceland Inc' On the ethics of commercial population genomics. Soc Sci Med 2004; 58: 1201 1209.

22 Árnason V: Coding and consent: moral challenges of the database project in Iceland. Bioethics 2004; 18: 27-49.

23 Hakonarson H, Thorvaldsson S, Helgadottir A et al: Effects of a 5lipoxygenase-activating protein inhibitor on biomarkers associated with risk of myocardial infarction: a randomized trial. JAMA 2005; 293: 2245-2256.

24 Crabtree BF, Miller WL: Doing Qualitative Research. Thousand Oaks, CA: Sage Publications, 1999.

25 Krueger R: Focus Groups. A Practical Guide for Applied Research. Thousand Oaks, CA: Sage Publications, 2000.

26 Kitzinger J: Introducing focus groups. BMJ 1995; 311: 299-302.

27 Barbour R, Kitzinger J: Dev Focus Group Res. London: Sage Publications, 1999.

28 Borkan J: Immersion/crystallization; in: Crabtree BF, Miller WL (eds): Doing Qual Res. Thousand Oaks: Sage Publications, 1999.
29 Malterud K: Qualitative research: standards, challenges, and guidelines. Lancet 2001; 358: 483-488.

30 Fleising U: From bank to bench to pharmacy shelf: Biotechnology and the culture of finance; in: Einsiedel EF, Timmermans F (eds): Crossing Over Genomics in the Public Arena. Calgary: University of Calgary Press, 2005.

31 Árnason A, Simpson B: Refractions through culture: the new genomics in iceland. Ethnos 2003; 68: 533-553.

32 Fortun M: Mediated futures in the genomics futures markets. New Genet Soc 2001; 20: 139-156.

33 Harmon-Jones E, Mills J: Cognitive Dissonance: Progress on a Pivotal Theory in Social Psychology. Washington, DC: The American Psychological Association, 1999.

34 Evans JH: Playing God?: Human Genetic Engineering and the Rationalization of Public Bioethical Debate. Chicago: The University of Chicago Press, 2002.

35 Eriksen EO, Weigard J: Understanding Habermas: Communicative action and Deliberative Democracy. London: Continuum International Publishing Group, 2004.

36 Taylor BC, Schreiner PJ, Stone KL et al: Long-term prediction of incident hip fracture risk in elderly white women: study of osteoporotic fractures. J Am Geriatr Soc 2004; 52: 1479-1486.

37 Cranney A, Waldegger L, Zytaruk N et al: Risedronate for the prevention and treatment of postmenopausal osteoporosis. Cochrane Database Syst Rev 2003.

38 Holtzman NA, Marteau TM: Will Genetics Revolutionize Medicine? N Engl J Med 2000; 343: 141-144.

39 Burke W, Zimmern RL: Ensuring the appropriate use of genetic tests. Nat Rev Genet 2004; 5: 955-959.

40 Epstein CJ: Genetic testing: hope or hype? Genet Med 2004; 6: $165-172$.

41 Pálsson G, Harðardóttir KE: For whom the cell tolls: debates about biomedicine. Currt Anthropol 2002; 43: 271-287.

42 Cohen S: The Nature of Moral Reasoning: The Framework and Activities of Ethical Deliberation, Argument and Decision-Making. South Melbourne: Oxford University Press, 2004.

43 Waterton C, Wynne B: Can focus groups access community views?; in: Barbour R, Kitzinger J (eds): Developing Focus Group Research: Politics, Theory and Practice. London: Sage Publications, 1999.

44 Defining a new bioethic. Nat Genet 2001; 28: 297-298. 